\title{
Práticas avaliativas na gestão da Atenção Básica à Saúde: estudo de caso em Camaquã e Canguçu (RS)
}

\author{
Juliana Maciel Pinto \\ Secretaria Municipal de Saúde de Porto Alegre (RS) \\ Tatiana Engel Gerhardt \\ Universidade Federal do Rio Grande do Sul
}

O artigo aborda a gestão municipal do Sistema Único de Saúde (SUS) a partir das práticas avaliativas realizadas em Camaquã e Canguçu (RS). Apresenta estudo de casos múltiplos, qualitativo, com análise de dados de observação participante, entrevistas semiestruturadas e documentos locais. Foram considerados os tipos de práticas avaliativas (cotidiana, normativa, pontual, de monitoramento ou investigação avaliativa) e a origem dos avaliadores (internos ou externos). Identificaram-se o predomínio de práticas avaliativas cotidianas exercidas por agentes internos e a presença de práticas normativas induzidas por agentes externos. Conclui-se que a mediação sociopolítica é a principal estratégia gestora para considerar a diversidade de atores e suas avaliações sobre um sistema de saúde que pretende atuar em rede e que tem a participação como diretriz constitucional.

Palavras-chave: atenção primária à saúde; gestão em saúde; avaliação em saúde; planejamento em saúde; população rural.

Prácticas de evaluación en la gestión de la Atención Primaria de Salud: un estudio de caso en Camaquã y Canguçu (RS)

El artículo aborda la gestión municipal del Sistema Único de Salud (SUS) desde las prácticas de evaluación llevadas a cabo en Camaquã y Canguçu (RS). Presenta múltiples estudios de casos, análisis de datos cualitativos con la observación participante, entrevistas semi-estructuradas y documentos locales. Se consideraron los tipos de prácticas de evaluación (cotidiana, normativa, puntual, o investigación evaluativa) y el origen de los evaluadores (interno o externo). Identificaron el predominio de las prácticas de evaluación cotidianas ejercidas por los agentes internos y la presencia de prácticas normativas inducidos por agentes externos. La conclusión és que la mediación es la principal estrategia de gestión socio-política a considerar la diversidad de actores y sus evaluaciones en un sistema de salud que tiene la intención de trabajar en red y cuenta con la participación como una directriz constitucional.

Palabras clabe: atención primaria de salud; gestión en salud; avaluación en salud; planificación en salud; población rural.

Artigo recebido em 23 nov. 2011 e aceito em 23 nov. 2012. 
Evaluation practices in the management of Primary Health Care: a case estudy in Camaquã and Canguçu (RS)

The article discusses the municipal management of the Unified Health System (UHS) from evaluation practices occurring in Camaquã and Canguçu (RS). Presents multiple case studies, qualitative data analysis with participant observation, semi-structured interviews and local documents. Were considered the types of evaluation practices (everyday, normative, punctual, monitoring or evaluative research) and the origin of the evaluators (internal or external). Identified the predominance of everyday evaluation practices exercised by internal agents and the presence of normative practices induced by external agents. It is concluded that the mediation sociopolitical is the main management strategy to consider the diversity of actors and their evaluations on a health system that intends to operate in a network and has participation as a constitutional guideline.

KEY WORDs: primary health care; health management; health evaluation; health planning; rural population.

\section{Introdução}

As tentativas de racionalização dos processos decisórios no setor público brasileiro são anteriores ao processo de consolidação legal do Sistema Único de Saúde (SUS). Neste caminho, os países latino-americanos utilizaram enfoques como o desenvolvimentista, com expressão no método Cendes-OPS (Centro Nacional de Desenvolvimento da Organização Pan-americana da Saúde), a planificação (Rivera, Testa e Matus, 1989), a epidemiologia (Campos, 1994) e o planejamento estratégico (Testa, 1992).

Na América Latina, as iniciativas de avaliação em saúde já têm três décadas e começaram com a avaliação de serviços e estabelecimentos de saúde (Paim, 2005). Também data da mesma década a pesquisa de avaliação de políticas de saúde no Brasil, tanto acadêmicas como na administração pública (Uchimura e Bosi, 2007). Já com os Sistemas Unificados e Descentralizados de Saúde (SUDs) houve certa valorização da avaliação por meio do uso dos primeiros planos estaduais e municipais de saúde, na década de 1980, mesmo não tendo avançado com a força merecida para o desenvolvimento do SUS.

O que se pode considerar é que, desde a instituição do SUS, muitos estudos voltaramse para discutir e desenvolver métodos de trabalho na gestão e planejamento dos serviços e sistemas de saúde. Havia, e ainda há, uma necessidade de incluir esses métodos no cotidiano do trabalho nos serviços de saúde e a capacidade reflexiva que eles exigem.

\section{A avaliação na gestão da saúde pública}

Na esfera das políticas públicas, a avaliação tem a pretensão de comparar um padrão almejado com a realidade, ao mesmo tempo que busca identificar a eficácia das ações aplicadas so- 
bre essa mesma realidade (Cohen e Franco, 2008). A avaliação é considerada um julgamento sobre uma determinada prática social, que busca responder a questões sobre essas práticas submetendo-as a métodos e técnicas que lhe confiram (alguma) objetividade (Silva e Formigli, 1994).

No processo de institucionalização da avaliação realizada no sistema de saúde brasileiro, que não é incipiente, há o predomínio da avaliação do tipo normativa, incluindo suas dimensões somativa e formativa. A avaliação normativa envolve o julgamento sobre uma intervenção quanto aos recursos empregados, à organização, a serviços e bens produzidos e a resultados obtidos (Contandriopoulos et al., 1997), constituindo-se em uma realidade predominante no SUS.

Da composição da avaliação normativa, a avaliação formativa é aquela que, desenvolvida ao longo dos programas, visa acompanhar o seu desenvolvimento. Já a avaliação somativa é a realizada ao fim de um programa, para verificar seus resultados e prestar contas (Silva, 2005). Estas correspondem à avaliação ex post, que pode ser realizada ao longo e ao término da implantação de um programa social (Cohen e Franco, 2008).

O predomínio dessa realidade avaliativa pode ser uma limitação aos gestores municipais se desconsiderar os elementos contextuais da realidade avaliada e não incluir os atores envolvidos na realidade nas reflexões sobre os resultados obtidos e sobre o processo avaliativo em si (Contandriopoulos et al., 1997). Caso a avaliação normativa seja desenvolvida apenas a partir de avaliadores externos e experts, ou então com a base em parâmetros avaliativos definidos a priori, as restrições analíticas podem ser ainda maiores.

A evolução das necessidades dos avaliadores e dos tomadores de decisão/gestores em face das questões em análise no cotidiano das instituições públicas resultou no reconhecimento teórico e prático da importância dos diferentes atores sobre os resultados das políticas públicas. Pela abordagem participativa, esta perspectiva de avaliação é compreendida como de quarta geração (Dubois, Champagne e Bilodeau, 2011) e converge com as incorporações no campo da avaliação em saúde pública, que também experimentou perspectivas anteriores, deslocadas do contexto de aplicação das políticas públicas e meramente prescritivas.

A perspectiva participativa da avaliação potencializa a polissemia de focos avaliativos na saúde (Uchimura e Bosi, 2007). Esses focos envolvem o provimento de recursos materiais suficientes nos serviços de saúde, o interesse dos profissionais e do serviço no desfecho de suas condutas no cuidado à saúde da população e o acesso aos serviços de saúde e seus determinantes. Envolvem, ainda, aspectos relacionados com a situação de saúde da população assistida, como suas formas de reprodução social (trabalho, educação, família, grupos de amigos e de vivência, e outros) e sua relação com a própria saúde.

A depender do contexto político em que se insere, a avaliação também é ferramenta para a negociação permanente e para a formação profissional mesmo no cotidiano onde as práticas acontecem (Brasil, 2005). Ao influenciar no direcionamento do processo de cuidado dos grupos populacionais, acredita-se que as práticas avaliativas também expressam a atenção à saúde prestada à população, assim como as práticas assistenciais. 
Pelo exposto, consideram-se práticas avaliativas em saúde as ações motivadas para o desvelamento de alguma necessidade em saúde (seja dos serviços e sistemas de saúde ou dos usuários), exercidas no cotidiano dos serviços e não esgotadas pelas ferramentas tecnológicas já existentes, nem pretendendo se tornar necessariamente técnicas a ser compartilhadas (Pinheiro e Silva Jr., 2008).

Conforme o modelo de gestão adotado e os objetivos institucionais, além da avaliação normativa se inclui o monitoramento (acompanhamento sistemático de alguns aspectos dos serviços ou da população) e a avaliação pontual (avaliação específica da realidade em um tempo limitado e pontual). As avaliações com perspectiva de identificação das necessidades, níveis de saúde e qualidade de vida da população vão desde as avaliações cotidianas (do tipo de satisfação de profissionais e usuários que definem uma ou outra ação e serviço como bons e ruins), ausentes de sistematicidade e de delimitação metodológica, até aquelas caracterizadas como uma investigação avaliativa, que utilizam de arsenal metodológico científico para execução e validação (Silva, 2005).

As investigações avaliativas - que são pesquisas acadêmicas com caráter avaliativo de políticas, programas e serviços de saúde (Silva, 2005) - têm a potencialidade de integrar as práticas avaliativas que se desenvolvem em sistemas municipais de saúde. A exemplo, os Estudos de Linha de Base (ELB) sobre o Projeto de Expansão e Consolidação da Saúde da Família (Proesf), ao tentarem impulsionar a pesquisa avaliativa na Atenção Básica à Saúde (ABS), possibilitaram a vivência de profissionais da gestão e da assistência à saúde com a pesquisa avaliativa e facilitam o processo de institucionalização da avaliação em saúde (Hartz, Felisberto e Vieira-da-Silva, 2008).

As práticas avaliativas qualitativas, inclusivas, centradas no usuário (Pinheiro e Martins, 2009; Gerhardt et al., 2009a), realizadas pelos próprios profissionais de saúde locais, entre estes e pesquisadores e com valorização do processo reflexivo permanente, são formas inovadoras de visualizar os serviços, os sistemas de saúde e a população.

Estas formas de avaliar podem ser pensadas complementarmente às avaliações que predominam o histórico de planificação do sistema de saúde brasileiro - normativas. Vislumbrase, com o exposto, um planejamento em saúde para além da doença, que assuma um caráter positivo por meio de um pensar em saúde (Testa, 1992) e que, com isso, pratique a avaliação para promover saúde.

\section{Contexto das práticas avaliativas}

Os dois municípios pesquisados são considerados de pequeno porte, por apresentarem menos que 70 mil habitantes (IBGE, 2011), e estão localizados na dita "Metade Sul" do estado do Rio Grande do Sul. Apesar desta semelhança no porte populacional, as características sociais e produtivas de ambos fazem com que tenham diferenças acentuadas.

Canguçu apresenta mais da metade da sua população vivendo em localidades rurais caracterizadas por minifúndios, onde é alvo de políticas públicas nesta área, enquanto o mu- 
nicípio de Camaquã caracteriza-se pela presença de latifúndios, pela aceleração do setor produtivo e do êxodo rural. Por esses motivos, esses municípios foram descritos como polos de estagnação e dinamismo social e produtivo da região Sul do estado (Beck et al., 2008).

A produção do conhecimento a partir da análise da administração pública destes espaços, ao considerar suas especificidades, pode induzir à hipótese de situações também diferenciais para a gestão da saúde pública. No entanto, um estudo tendo como foco a gestão do cuidado em 13 municípios da região Sul do estado do Rio Grande do Sul evidenciou as dificuldades de gestores municipais em conceituar um de seus instrumentos e um de seus objetos de trabalho: a informação em saúde e a ABS (Pinto, 2008). Sugere que as diferenças apresentadas para os sistemas produtivos e sociais em Becker e colaboradores (2008) podem não estar presentes em todas as suas dimensões, como na saúde pública.

De forma específica à realidade de Canguçu, estudo de Riquinho (2009), ao identificar os serviços de saúde esporádicos na zona rural e sua predominância na zona urbana, constatou que os caminhos percorridos nos itinerários terapêuticos eram plurais, diversos e podemse identificar relações formais ou informais interessadas. Estas podem reforçar, muitas vezes, redes complexas de relações de poder assimétricas, assistencialistas e clientelistas nos planos macro e microssocial, representados pelo poder público local (Gerhardt et al., 2009a).

Quanto ao município de Camaquã, conforme o Plano Diretor de Regionalização do Estado do Rio Grande do Sul (PDR/RS), o município é referência microrregional para consultas e procedimentos de média complexidade, atendendo a outros municípios arredores (Gerhardt et al., 2009b; Roese, 2005). Com isso, importa saber, entendendo-se ABS como uma responsabilidade executiva exclusiva do município, se a gestão local de saúde de Camaquã está identificando e atendendo às necessidades de saúde da sua população no âmbito da ABS.

As contribuições do presente estudo serão importantes na medida em que a compreensão das práticas avaliativas, desenvolvidas no sistema municipal de saúde para a gestão da ABS, possibilita: 1) reconhecer que os cuidados em saúde vão além do conhecimento normativo repassado às equipes de gestão municipal em saúde pelas demais esferas de gestão do SUS, que têm capacidade de ação e resolutividade limitados no meio rural e local; 2) reconhecer que há potencialidades e limitações no uso de instrumentos de gestão disponíveis para atendimento à população e para a reflexão sobre o trabalho na gestão municipal da ABS. Nessa perspectiva, o estudo das relações dos profissionais da gestão da ABS com as práticas avaliativas busca a compreensão dos cenários e desenhos locais de gestão, incluindo as estratégias utilizadas para a melhoria da atenção e do cuidado à saúde da população rural.

\section{Objetivo}

Analisar a gestão municipal da ABS por meio da análise das práticas avaliativas desenvolvidas em dois municípios de pequeno porte da região sul do estado do Rio Grande do Sul. 


\section{Metodologia}

Trata-se de um estudo de casos múltiplos do tipo qualitativo, com caráter exploratório e descritivo. O uso de estudos de casos múltiplos, mesmo quando se trata de apenas dois casos em estudo, permite estabelecer contrastes entre os casos estudados (Gil, 2009).

O campo de estudo foram as Secretarias Municipais de Saúde (SMSs) de Camaquã e Canguçu, municípios da região Sul do Rio Grande do Sul. A coleta dos dados ocorreu no ano de 2010 e envolveu três etapas distintas, porém complementares para a compreensão da realidade explorada e descrita. A primeira etapa envolveu a coleta de documentos como Plano Municipal de Saúde (PMS), Relatórios de Gestão (RGs) e outros documentos elaborados e apontados pelas SMSs e que existam a partir do Pacto pela Saúde - 2006. A segunda e a terceira etapas, de entrevistas e observações participantes, ocorreram concomitantemente.

A escolha dos gestores a serem entrevistados considerou as funções que o cargo lhes confere para a organização, condução e desempenho da gestão da ABS no que tange à população rural. Foram excluídos do estudo aqueles profissionais que não têm como foco de trabalho a gestão da ABS e os que se recusaram ou desistiram de participar. No total, foram entrevistados sete gestores entre os dois municípios.

As equipes envolvidas com a população rural foram identificadas e descritas a partir das observações participantes, que objetivaram a identificação, descrição e compreensão das práticas avaliativas desenvolvidas no dia a dia do trabalho na gestão em saúde.

A elaboração das categorias de análise foi orientada pela tipologia de práticas avaliativas consideradas por Silva (2005): cotidiana, normativa (formativa ou somativa), pontual, de monitoramento e investigação avaliativa. A partir dessa definição teórica, a organização dos dados concordou para a categorização e análise temática (Minayo, 2008), auxiliadas pelo software NVivo8 ${ }^{\circledR}$.

A análise das práticas avaliativas foi complementada, ainda, com a descrição sobre posição dos avaliadores: avaliadores externos (experts, pesquisadores ou consultores), avaliadores internos (equipe gestora da SMS, profissionais assistenciais ou a população usuária do sistema público de saúde) (Silva, 2005; Cohen e Franco, 2008).

As considerações bioéticas foram respeitadas, conforme Resolução no ${ }^{-196}$, de 10 de outubro de 1996, do Conselho Nacional de Saúde (Brasil, 1996) e parecer de aprovação ํㅜㅇㅡ. 2008077, do Comitê de Ética da Universidade Federal do Rio Grande do Sul (CEP/UFRGS). Com o exposto, os participantes entrevistados receberam identificações fictícias, sendo Gestor-A1, A2, A3 e A4 aqueles de Camaquã e Gestor-B1, B2 e B3 aqueles de Canguçu, incluindo o recebimento do Termo de Consentimento Livre e Esclarecido (TCLE).

\section{Tipologia das práticas avaliativas em saúde na esfera municipal do SUS}

Os tipos de práticas avaliativas identificadas caracterizam as necessidades locais de organizar o trabalho como parte da práxis da gestão em saúde. Dos cinco tipos de avaliação descritos 
por Silva (2005), características de quatro delas foram identificadas neste estudo de casos: a) avaliação cotidiana; b) avaliação pontual; c) monitoramento; e d) avaliação normativa.

Os motivos de realização e os agentes envolvidos caracterizam as práticas avaliativas. Assim, os agentes avaliadores internos e externos foram descritos pelo espaço que ocupam no SUS (quadro 1).

\section{Quadro 1}

\section{Práticas avaliativas em saúde na gestão local do SUS em Camaquã e Canguçu (RS)}

\begin{tabular}{|c|c|c|c|}
\hline \multirow{2}{*}{$\begin{array}{l}\text { Tipos de práticas } \\
\text { avaliativas }\end{array}$} & \multirow[b]{2}{*}{ Motivos de avaliação } & \multicolumn{2}{|c|}{ Agentes avaliadores } \\
\hline & & Camaquã (RS) & Canguçu (RS) \\
\hline \multirow[t]{5}{*}{ COTIDIANAS } & $\begin{array}{l}\text { Níveis de saúde e doença } \\
\text { em determinados grupos } \\
\text { populacionais }\end{array}$ & $\begin{array}{l}\text { Gestão municipal } \\
\text { População }\end{array}$ & $\begin{array}{l}\text { Gestão municipal } \\
\text { População }\end{array}$ \\
\hline & $\begin{array}{l}\text { Verificar a eficácia de serviços e } \\
\text { ações }\end{array}$ & $\begin{array}{l}\text { Gestão municipal } \\
\text { População }\end{array}$ & Gestão municipal \\
\hline & $\begin{array}{l}\text { Satisfação de usuários e } \\
\text { profissionais }\end{array}$ & $\begin{array}{l}\text { Gestão municipal } \\
\text { População } \\
\text { ACS }\end{array}$ & $\begin{array}{l}\text { Gestão municipal } \\
\text { Profissionais assistenciais }\end{array}$ \\
\hline & Regulação normativa e legal & $\begin{array}{l}\text { Gestão municipal } \\
\text { Órgão controlador externo } \\
\text { - Tribunal de Contas }\end{array}$ & \\
\hline & $\begin{array}{l}\text { Verificar a eficácia do modelo } \\
\text { tecnoassistencial }\end{array}$ & & $\begin{array}{l}\text { Gestão municipal } \\
\text { Profissionais assistenciais } \\
\text { Coordenações da SMS }\end{array}$ \\
\hline \multirow[t]{3}{*}{ PONTUAIS } & Regulação normativa & Gestão municipal & Gestão municipal \\
\hline & $\begin{array}{l}\text { Níveis de saúde e doença } \\
\text { em determinados grupos } \\
\text { populacionais }\end{array}$ & Gestão municipal (PMS) & \\
\hline & $\begin{array}{l}\text { Verificar a eficácia de serviços e } \\
\text { ações }\end{array}$ & Gestão municipal (PMS) & Gestão municipal \\
\hline \multirow[t]{3}{*}{ MONITORAMENTO } & $\begin{array}{l}\text { Verificar a eficácia de serviços e } \\
\text { ações }\end{array}$ & Gestão municipal & Coordenadores da SMS \\
\hline & $\begin{array}{l}\text { Regulação dos recursos } \\
\text { orçamentários da SMS }\end{array}$ & Gestão municipal & \\
\hline & $\begin{array}{l}\text { Regulação da assistência } \\
\text { farmacêutica }\end{array}$ & Gestão municipal & Gestão municipal \\
\hline \multirow[t]{2}{*}{ NORMATIVAS } & $\begin{array}{l}\text { Níveis de saúde e doença } \\
\text { em determinados grupos } \\
\text { populacionais }\end{array}$ & $\begin{array}{l}\text { Gestão municipal } \\
\text { SUS Estadual - CRS }\end{array}$ & $\begin{array}{l}\text { Gestão estadual } \\
\text { Gestão municipal (PMS e } \\
\text { Relatórios de Gestão) }\end{array}$ \\
\hline & $\begin{array}{l}\text { Verificar a eficácia de serviços e } \\
\text { ações }\end{array}$ & Gestão municipal & Gestão municipal \\
\hline
\end{tabular}

Fonte: Relatório de Pesquisa (PINTO, 2010).

Siglas: SMS = Secretaria Municipal de Saúde; RS = Rio Grande do Sul; ACS = Agentes Comunitários de Saúde; PMS = Plano Municipal de Saúde; SUS = Sistema Único de Saúde; CRS = Coordenadoria Regional de Saúde. 
Nos dois municípios pesquisados nenhuma pesquisa avaliativa foi relatada e nem observada no período da coleta de dados. Sobre este ponto, a necessidade de aproximação com as universidades próximas, para o desenvolvimento municipal do SUS, foi expressa em um dos PMS das secretarias municipais em estudo, porém não foi observada ou relatada no período pesquisado.

\subsection{Práticas avaliativas na Secretaria Municipal de Saúde de Camaquã (RS)}

Neste estudo de caso, os tipos de práticas avaliativas caracterizaram-se por: práticas cotidianas, demandadas pela população e pelos profissionais assistenciais e de gestão; práticas pontuais, estimuladas por demandas específicas de agentes externos; práticas programáticas, emergentes de necessidades internas à realidade da gestão municipal; e práticas permanentes estimuladas a partir de atores externos.

\section{A. Avaliação cotidiana: descrição empírico-perceptiva das vivências na cidade por gestores, trabalhadores e usuários}

Como "recurso a noções oriundas do senso comum, não sistematizadas de observação e análise e juízos de valor dicotômicos e simplificados" (Silva, 2005), a avaliação cotidiana inclui o julgamento do profissional de saúde sobre o serviço em que atua, a satisfação dos usuários que definem o serviço como bom ou ruim, bem como de outros atores externos que fazem o mesmo trajeto reflexivo.

Os entrevistados relataram a percepção de fatores relacionados com as situações de saúde da população. Referem-se: 1) à prevalência de cânceres e o uso de agrotóxicos nas lavouras (Gestor-A3); 2) ao aumento das Doenças Crônicas Não Transmissíveis (DCNT) e a não adesão e seguimento incorreto a tratamentos medicamentosos e cuidados alimentares (Gestor-A3); 3) ao aumento dos processos de adoecimento e o fim das equipes da ESF (Gestor-A1); e 4) à maior necessidade de atenção à população urbana periférica do que à população rural, pela vulnerabilidade atual vivida pela primeira (Gestor-A2).

Eles plantam fumo. Eles trabalham muito com o veneno do fumo. Às vezes eu questiono a nossa água da barragem. A serra toda trabalha com fumo. Durante as chuvas a água entra na barragem, e o fumicultor trabalha com muito inseticida, com muito agrotóxico. E assim ó, nós bebemos agrotóxico! O índice de pacientes com câncer em Camaquã é muito alto. Se questiona até que ponto, como é a nossa água, porque é toda a serra. (Gestor-A3)

Foram relatadas demandas que, impressas na população assistida, mobilizam os gestores a perceber essas situações e agir. Essa foi a situação de Gestor-A2, que identifica a neces- 
sidade de mudança da marcação de exames e consultas pela dificuldade constante que residentes rurais tinham para acessá-los, e a situação associada relatada pelo Gestor-A4:

E na população rural mais problemas psiquiátricos. (...) Muita mulher com depressão, muita mulher. E os homens o alcoolismo né. Aí tem a questão da agressão física, da violência doméstica... (...) Tudo isso. E é um problema bem sério né, e infelizmente a gente tem um número reduzido de atendimento desse tipo de doença. É meio complicado, a gente não consegue encaixar todo mundo. Mesmo que a pessoa queira se tratar é muita procura pra pouco médico, porque a gente não tem quase psiquiatra. (Gestor-A4)

Os descontentamentos apontados sobre o funcionamento do sistema público de saúde vêm dos próprios profissionais e de outros atores, não usuários, que exigem reconhecimento em suas situações de saúde e de trabalho no SUS municipal. As mobilizações são realizadas internamente, mas também por influência da população e de outras forças sociais e políticas que mobilizam a equipe gestora a olhar para os problemas que apontam.

Atentam para a necessidade de reconhecimento das condições e situações vividas por trabalhadores e demais grupos populacionais no município por meio de seus porta-vozes (rádio, vereadores, líderes comunitários etc.). Houve a explicitação midiática local de problemas da SMS (Gestor-A1) e, reconhecendo esses problemas, foram iniciados processos importantes para a modificação de algumas práticas organizacionais.

Nós estamos marcando exames todos os dias da 13h30min às cinco. Fila que tem? 40 pessoas, 30 pessoas. 50 pessoas, 20 pessoas. Acabou a fila. Aí [antes] vinha a rádio para aí, "por que o SUS é isso aí, é isso aí, é só fila. Por que o SUS é isso aí, é só fila. Porque pagam pouco, por isso as pessoas têm que ficar aí". Porque aí, a uma e meia da manhã ele vinha para a fila, né. (...) Porque as pessoas têm que vir de casa uma e meia da manhã, ficar aí no frio, no inverno, na chuva, passando por isso daí. Aí vinha duas rádios aí, mais (...). (Gestor-A1)

Gestor-A2 desenvolve um trabalho de mediador na avaliação das possibilidades de mudanças organizacionais demandadas externamente. Assim, os gestores avaliam previamente suas possibilidades conforme os recursos materiais e de trabalhadores disponíveis e conforme a posição dos demandantes (população, rádios, câmara dos vereadores, órgãos avaliadores e controladores externos, categorias profissionais etc.).

(...) Embora, como é que eu vou te dizer, embora tenha ampliado, na população rural, tenha ampliado muito o número de locais de atendimento e consultas. Embora sejam coisas assim que, como é que eu vou te dizer... "vamos colocar uma unidade de atendimento lá uma vez por semana ou quinzenal, lá em determinado bairro". Às vezes, até por uma solicitação de um determinado candidato a vereador ou vereadora, "ó, lá precisa porque a população é assim e assim, fica distante". "E tudo bem, vamos colocar." Então, se passa a ter aquele atendimento lá. (...) (Gestor-A2) 
As reuniões com os ACS também trazem essas características das práticas avaliativas, motivadas pelas vivências com as demandas populacionais. Estes externaram preocupação com a forma como os profissionais assistenciais se relacionam com a população. Para o Gestor-A3 há obviedade na construção deste tipo de apontamento, tendo em vista a dimensão da vivência cotidiana com a população.

Acho que avaliação em saúde é o que a gente faz todos os dias. É o que a gente, é o que tu faz pra conseguir atender a população, é o que, a maneira como tu corre atrás e como tu planeja e tu executa as ações propostas, as estratégias. (Gestor-A3)

Apesar de reconhecer essa dimensão cotidiana da avaliação pelos profissionais, o Gestor-A2 aponta limitadores da institucionalização de práticas avaliativas. Associa a incapacidade no desenvolvimento de avaliação e projetos institucionais à interferência e sobreposição de demandas pessoais dos profissionais e de relações político-partidárias na SMS.

Esta categoria, da avaliação cotidiana, evidencia que há um composée de atores para o direcionamento executivo das ações e estrutura da SMS. Os entrevistados reconhecem essa realidade e demonstram atuar na perspectiva de apresentar soluções às demandas apontadas.

\section{B. Ou oito ou oitenta: avaliação pontual como análise emergencial e como cumprimento normativo}

Esta categoria está relacionada a uma dificuldade encontrada na condução da SMS e refere-se a uma situação em curso quando da coleta de dados no município - em ato.

Lembra-se que uma avaliação pontual é aquela que "parte de uma avaliação específica com tempo de realização delimitado" e a prática avaliativa identificada foi realizada para suprir uma demanda de regulação legal apontada pelo Tribunal de Contas. As demandas eram: inclusão dos profissionais assistenciais da Estratégia de Saúde da Família (ESF) no Índice da Folha de Pagamentos com servidores públicos e respeitando à Lei de Responsabilidade Fiscal.

$\mathrm{O}$ atendimento às demandas influenciou a estrutura organizacional da SMS na ABS, pois a escolha da equipe de gestão foi a desestruturação do atendimento no modelo da ESF, com demissões dos ACS.

O que deu para perceber, com essa escolha de mexer com o PSF e PACS, é que, como esses "programas" foram ideia do Governo Federal, e não como uma iniciativa surgida no município, eles serão postos em segundo plano pela SMS na escolha de "onde cortar" gastos. (Obs. Cam. 4)

Em Camaquã, o período de elaboração do PMS significa um período esporádico de reflexão sobre a prática gestora e a situação de saúde da população, sendo motivado apenas por 
demanda externa - troca de gestão. Essa foi a justificativa para a não elaboração dos dois últimos PMSs, referentes aos triênios 2005-08 e 2008-11, tendo em vista a continuidade da gestão atual em dois mandatos seguidos.

\section{Práticas de monitoramento: regulação do prestador privado e de aplicação orçamentária}

De forma inversa às práticas de avaliação caracterizadas como pontuais, o monitoramento remete a situações que precisam ser acompanhadas ao longo do tempo. A prática de monitorar foi identificada na relação com o prestador privado, regulado para o cumprimento do contrato de prestação de serviços. Na análise da execução de serviços, o gestor acompanha um conjunto de informações específicas no contrato de prestação de serviços com um hospital local e com laboratórios de análises clínicas.

Ao acompanhar os serviços contratados e sua produtividade geral, a gestão da SMS tenta identificar falhas na prestação dos serviços contratados, compreendê-las e minimizá-las.

E hoje, a grade do hospital tem dois furos: terça e quinta a parte da tarde não têm plantonista, que seriam obstetras, por que ninguém quer atender. $\mathrm{E}$ os dois que se tem não têm disponibilidade. (...) Não querem atender os que vêm de fora, porque o SUS paga pouco, e os que têm na cidade não têm porque só têm dois. Então, a gente enfrenta esse tipo de coisa. Qualquer coisa que acontece no hospital a culpa é da Secretaria de Saúde. Mas, a Secretaria da Saúde coloca 160 mil mensais. Ninguém vê isso. (Gestor-A1)

As realidades identificadas no monitoramento podem direcionar as ações futuras e justificar as necessidades de aplicação de recursos financeiros na saúde. O Gestor-A1 relata ter que saber sobre todos os investimentos e custos executados na SMS para justificá-los diante das demais secretarias e do prefeito, ou seja, estão atrelados ao controle orçamentário.

\section{Práticas avaliativas normativas: condicionamentos da gestão descendente na rotina da gestão municipal do SUS}

As práticas avaliativas com características de avaliações normativas, relatadas por Gestor-A3 e Gestor-A4, são aquelas realizadas pela exigência de programas de políticas públicas específicas (p. ex., pré-natal, HiperDia, saúde do trabalhador). Preveem tanto a avaliação formativa (no desenvolvimento do programa) quanto a somativa (realizada ao final).

Para o Gestor-A3, todas as práticas avaliativas executadas fazem parte da dimensão técnica da atenção à saúde e têm predeterminações do gestor municipal. São, portanto, consideradas práticas normativas. 
E aí a gente trabalha dentro do que é preconizado pelo município, do que é preconizado pelo gestor né, do número $\mathrm{X}$ de atendimentos, do número do... Trabalha já com uma estrutura préinstituída. (Gestor-A3)

Reforça, ainda, que há uma direção única - municipal - no sistema de saúde, mas em conformidade com as demais esferas gestoras. Como sua função é coordenadora, exige e monitora a realização das ações pelas unidades, que periodicamente devem prestar contas.

Nota-se, aqui, que as práticas avaliativas realizadas por Gestor-A1 e Gestor-A2 não focaram características de avaliação normativa. A hipótese dessa constatação é que o tipo de avaliação se relaciona aos cargos ocupados por estes quatro atores na gestão, sendo Gestor-A3 e Gestor-A4 ocupando cargos que se situam na dimensão da atenção à saúde, e Gestor-A1 e Gestor-A2, cargos que se situam na dimensão administrativa da gestão da SMS.

Assim são tratados o PMS e os RG. A utilização destes dois documentos não foi observada, mas foi referido por Gestor-A2 que as suas elaborações estão entre as suas atribuições. Logo, os RG e o PMS são tratados como atividades pontuais, não como norteadoras da execução do trabalho em saúde.

As práticas avaliativas com formato de avaliações pontuais se destacaram neste caso, sendo reforçadas pela relação dos gestores entrevistados com os documentos de planejamento da SMS - PMS e RG — e pela situação específica da ESF e dos ACS, ocorrida no período da coleta de dados e focada no controle da execução orçamentária.

\subsection{Tipos de práticas avaliativas para o caso de Canguçu (RS)}

As práticas avaliativas em saúde em Canguçu caracterizaram-se por: práticas cotidianas, estimuladas pelos profissionais assistenciais e da gestão; práticas pontuais e de monitoramento, estimuladas por problemas e ajustes nos processos de trabalho dos serviços de saúde; e práticas normativas estimuladas por políticas públicas induzidas por agentes externos ao cotidiano municipal.

\section{A. Identificação das necessidades na vivência cotidiana: percepção de ineficiência sobre o modelo de atenção à saúde e o papel dos mediadores rurais e profissionais na SMS}

Todas as falas de Gestor-B1, Gestor-B2 e Gestor-B3 referem-se a vivências no cotidiano da SMS e associam-se à posição que ocupam na gestão. Gestor-B1 refere-se às dificuldades de modificar o modelo de atenção à saúde para um enfoque da prevenção e da promoção à saúde, com unidades de saúde do tipo ESF em toda a extensão municipal — urbana e rural.

Ainda estamos trabalhando por uma, vamos dizer assim, por uma demanda histórica, por uma cultura da população. Continuamos ainda com a maior parte, uma percentagem maior, vamos 
dizer assim, 70, 80\% ainda trabalhando em cima da medicina curativista. Que não é o ideal para $\operatorname{mim} . .$. (...). (Gestor-B1)

Entre os motivos apontados estão a construção social do Pronto Atendimento como lugar predominante de atenção à saúde do público para a população. Outro motivo, relatado por outro integrante da equipe assistencial, é causado pelo clientelismo político que norteia a oferta de serviços de saúde no município e fortalece o modelo de atenção vigente.

A depender da intensidade com que determinadas questões se apresentam e são percebidas pelos gestores, o julgamento sobre elas se complexifica em suas variantes. Este é o caso da necessidade, sentida e compartilhada pela equipe gestora e assistencial, de mudança de modelo assistencial.

Na avaliação cotidiana sobre a situação de saúde da população, o Gestor-B1 afirma que determinados problemas em saúde são acentuados na população rural, como o uso indiscriminado de antidepressivos. Como avaliação dessa situação, relaciona esse problema de saúde ao ambiente no rural, bucólico.

E eles demandam muita, muita medicação controlada. Eu entendo assim que é um pouco do ambiente do interior que deixam as pessoas, muitas pessoas mais infelizes assim, mais tristes, mais depressivos. (Gestor-B1)

Ainda para a identificação das necessidades da população rural, o Gestor-B3 relata que há uma importante fonte de dados e de avaliação sobre as necessidades de atendimentos e de saúde da população rural. Esta o auxilia no delineamento das situações de saúde desta população e está representada pelos presidentes das associações e líderes comunitários rurais.

O que eu acho que ajuda é o que os próprios presidentes das associações comunitárias colocam pra gente. Da necessidade daquela comunidade. Da população que vive ali. (...) Eles contam pra gente: "Aí, a gente tem dificuldade disso. Lá tá precisando de médico. Lá tá precisando mais um dentista. Tem um monte de mulheres que querem fazer o pré-câncer que ainda não fizeram". Então tudo isso aí eles informam a gente. (Gestor-B3)

As avaliações qualitativas dos presidentes de associações e líderes comunitários sobre a atuação da SMS são vistas pelos entrevistados como "ferramentas potenciais" para a gestão, tendo em vista suas avaliações sobre a atuação dos profissionais no atendimento e o levantamento das demandas nas localidades de que fazem parte. Na mesma perspectiva, o Gestor-B2 refere que recebe o apoio das coordenações dos serviços de saúde, que também realizam o levantamento das necessidades e procuram os gestores em situações-problemas vividos nos seus serviços.

A partir das considerações populares e dos profissionais assistenciais, os gestores trocam informações, agem, remodelam e reconduzem o SUS municipal. Concretizam uma prá- 
tica avaliativa norteada pela mediação gestora entre aqueles que realizam suas avaliações cotidianas sobre os serviços de saúde e as condições de saúde da população rural.

\section{B. Avaliações pontuais: estímulos para a qualificação da tomada de decisão}

A avaliação pontual relatada por Gestor-B2 foi motivada pelo gasto em medicamento controlado. Os gestores observaram um descompasso entre o dispensado em medicamentos e o receitado pelos médicos da SMS.

Ano passado que Gestor-B1 levantou, questionou isso aí, Gestor-B1 buscou né. O índice de medicação que estava saindo realmente estava muito alto, muito alto. E é uma coisa que sei lá, que no dia a dia aqui na Secretaria é tão corrido que, às vezes, tu não vê o mal maior. (Gestor-B2)

A avaliação pontual foi gerada a partir de uma percepção interna (avaliação cotidiana) dos gestores e dos próprios profissionais assistenciais, que questionaram um processo administrativo e operacional comum ao cotidiano na SMS e decidiram por avaliá-lo especificamente.

A regulação desse processo de trabalho em saúde, incluindo alguns cuidados que envolvem a terapia medicamentosa, foi a alternativa escolhida pela gestão da SMS. A partir daí, os profissionais assistenciais passaram a racionalizar a própria atuação no tema.

Quando incluído na sensibilidade da equipe gestora, o levantamento dos problemas de funcionamento e estrutura torna-se questão a ser refletida pontualmente em equipe. Assim, há questões cotidianas que saem desse status e incorporam um status "pontual", compondo as práticas avaliativas da gestão municipal.

\section{Monitoramento para o controle de mudanças instituídas na assistência e na gestão}

O monitoramento de dados e informações aparece como motivado por uma avaliação pontual. Neste caso, a regulação do uso de medicamentos com receituário controlado foi instituída a partir de levantamento pontual, realizado pela equipe gestora, que gerou a mudança nos processos de trabalho envolvidos.

Agora, depois que começou essa parte que Gestor-B1 buscou o levantamento pra ver por que a fila estava muito grande, que a gente começou a frear em todos os lugares da saúde essas receitas controladas. Se vai pra um posto para um PSF a gente anota - a data que foi, a quantidade que foi e fica sempre aqui na sala do Gestor-B1. Se vai aqui pro Pronto Atendimento, se vai pro CAPS $\mathrm{AD}$ ou pro outro CAPS, sempre anotar a data que foi. (Gestor-B2)

Diferentemente desta situação, nos RG não foi apresentado o monitoramento dos programas governamentais inscritos no PMS 2005-09. 


\section{Práticas avaliativas normativas: adaptações gerenciais para a implantação de programas de políticas públicas no cotidiano municipal}

Uma prática avaliativa com característica normativa, exercida a partir de um programa do governo estadual, foi explicitada por Gestor-B1. Esse propõe a ampliação do programa, afirmando que problemas do escopo do programa, como os acidentes de moto, são comuns no município por se tratar de meio de transporte comum aos residentes rurais, com e sem habilitação. Essa fala evidencia uma das finalidades dos programas governamentais das esferas estadual e federal, que atuam como indutores da governabilidade local.

Outra prática, relacionada à avaliação normativa, é a utilização cotidiana do cadastro HiperDia. Esta está designada ao profissional da nutrição, que atende a todos os munícipes com hipertensão e/ou diabetes. Nesta área, a gestão da atenção à saúde da população rural afirma não acompanhar nem para rastrear a população rural usuária do serviço.

(...) Então tudo isso é feito lá e essas pessoas são cadastradas no HiperDia. Aí isso tudo está no posto central. Se tu quiseres esses dados tem que falar com ela. (Gestor-B3)

A fala sobre o HiperDia evidencia uma fragmentação, com a centralização da atenção à saúde de hipertensos e diabéticos justificada por um instrumento normativo de monitoramento e pela avaliação normativa. Por fim, destaca-se que os entrevistados não mencionaram a utilização do PMS e dos RG como instrumentos de avaliação.

Como para o caso de Camaquã, a realidade das práticas avaliativas na SMS de Canguçu também demonstra o predomínio de práticas avaliativas com características de avaliação cotidiana, ou seja, sem rigorosidade metodológica, não programada e perceptiva. Da mesma forma, as avaliações pontuais estão relacionadas a problemas na condução do Sistema Local de Saúde e o monitoramento priorizado é atrelado a estes problemas.

\section{Análise das práticas avaliativas na gestão do SUS: arranjos sociais e demandas avaliativas na esfera municipal}

Neste estudo de casos se evidenciou que as práticas avaliativas no nível da situação de saúde das populações dos municípios em estudo são realizadas por quem está mais próximo à assistência direta da população. Os profissionais dos serviços de saúde e os presidentes das associações comunitárias rurais são os avaliadores com reconhecimento institucional quando o assunto é a saúde da população rural.

Como lideranças, têm capacidade de mobilização de recursos e bens humanos e não humanos, caracterizados como formas diversas de apoio às pessoas nos problemas que apresentam (Martins, 2009). Os recursos são mobilizados pelos agentes conforme a capacidade de articulação e a representação social que tenham na comunidade e fora dela. 
A identificação dos perfis avaliadores das SMSs conclui que as deliberações das demais esferas de gestão são indutoras, mas não definidoras. Exemplo disso foi a não utilização dos PMSs e RGs para as práticas avaliativas nos municípios.

Já as práticas avaliativas cotidianas estão impregnadas no fazer gestor e compõem o imaginário e as trocas cotidianas com atores diversos, como políticos, líderes comunitários, mídia local e a população de forma direta. Enquanto as práticas avaliativas pontuais e normativas têm a potencialidade de gerar mudanças de caráter estrutural no sistema municipal de saúde, as práticas avaliativas cotidianas exigem, principalmente, a atuação imediata sobre as demandas geradas, a depender do agente propulsor da avaliação, e geram mudanças incrementalistas cotidianas no sistema de saúde.

As práticas pontuais são justificadas pelas cobranças no nível da legalidade a que estão dispostas, quando estimuladas por meio de órgãos controladores competentes. Neste ponto, essas práticas provocam momentos de crise no espaço dos atores cotidianos, mobilizando-os para a manutenção da situação anterior ou para esclarecimentos sobre as mudanças normativas exigidas externamente à realidade municipal.

Conclui-se que as práticas avaliativas normativas, mesmo realizadas a partir de agentes externos ou experts (Contandriopoulos et al., 1997), podem gerar mudanças estruturais na condução do sistema, desde que atreladas a exigências legais. Ou seja, conduzem os gestores a avaliar e decidir sobre o caminho a seguir a partir das condições impostas.

Podem-se caracterizar as práticas avaliativas cotidianas como incrementalistas e reformistas, não gerando grandes rompimentos no cotidiano do sistema e serviços de saúde. Com isso, podem conduzir à estagnação do sistema de saúde por incidir sobre demandas de apenas alguns grupos, podendo não ser significativo para o conjunto da população.

De outra forma, o dinamismo na gestão municipal em saúde não necessariamente significa o aperfeiçoamento do sistema de acordo com as necessidades de saúde, de capacidade instalada e de apoio técnico. Mudanças significativas podem ocorrer por rompimentos de projetos em execução, afetando as relações dentro do sistema. Essas situações de crise podem forçar à reinvenção positiva ou negativa para o desenvolvimento do SUS e dos atores implicados.

Nos dois municípios essa realidade foi constatada, por motivos diferentes, mas destacase aquela identificada em Camaquã, relacionada à obrigatoriedade de adequar o orçamento e o gasto municipal com a inclusão dos profissionais da ESF na folha de pagamentos com quadro permanente de pessoal na SMS. Essa reorganização gerou uma crise que exigiu um movimento pontual, onde o núcleo da gestão da SMS refletiu sobre as possibilidades de mudanças e o impacto político e assistencial que acarretaria, incluindo a discussão com estratégias de comunicação e interlocução, por meio de arenas públicas como a Câmara de Vereadores e rádios locais.

Como estratégia, os gestores envolvidos nesta situação se mostraram ativos para solucionar o problema que atinge a manutenção do lugar dos atores no governo municipal, mesmo que não da mesma forma, e a necessidade assistencial da população sob sua adscrição. Em outras palavras, a avaliação realizada evidenciou o olhar gestor encerrado nas vivências 
e modos de sentir e pesar os espaços sociais e suas representações, não se limitando aos aspectos técnicos.

As práticas de monitoramento observadas, em ambos os casos, acompanharam mudanças de processos de trabalho a partir de demandas avaliativas pontuais originadas pelas equipes gestoras. Logo, foi evidenciado que as práticas avaliativas do tipo monitoramento são capazes de estimular o reconhecimento do gestor como regulador do SUS. Em ambos os casos, os monitoramentos estavam associados à necessidade de otimizar o uso dos recursos disponíveis para o funcionamento do sistema de saúde.

Em ambos os casos, evidenciou-se a marginalidade com que foram referidos os dados e informações provenientes dos Sistemas de Informações em Saúde (SISs) para o apoio à tomada de decisão pelos gestores municipais. A análise desse fenômeno é auxiliada pela compreensão de que a lógica operacional e técnica não deveria estar dissociada da lógica das relações, das condutas e regras sociais, como se fossem governos de coisas e de homens distintamente (Testa, 1992).

Destaca-se que os SISs são ferramentas com origem nas esferas estadual e federal do SUS, sendo utilizadas por estes atores externos para a avaliação normativa. Assim, as práticas avaliativas nos municípios são complementadas pelas avaliações e tentativas de regulação exercidas pelas demais esferas por meio dos seus SIS.

Ao pouco uso local dos SISs e à escolha de outras fontes para a realização das práticas avaliativas somam-se, em ambos os casos, a justificativa de ineficiência, a incerteza na veracidade das informações geradas pelos dados enviados às demais esferas de gestão (Pinto, 2008).

O pouco uso dos RGs e do PMSs também é evidência para ambos os casos estudados, sendo referido apenas como uma exigência da Secretaria Estadual de Saúde (SES) e de interesse prático para os avaliadores externos à realidade municipal. Estes são viabilizados na esfera municipal pelas exigências legais; para o RG, supõe modelos específicos definidos e disponibilizados pela SES para a inclusão dos dados, enquanto, para o PMS, inclui a apresentação de programas de indução estadual e federal, mas não observados na prática gestora dos dois municípios.

Nestes casos, as elaborações dos PMSs e RGs são atividades potencialmente normativas, mas ainda apresentadas de forma pontual. Ambos não foram referidos por mais que um entrevistado em cada município pesquisado, evidenciando a pessoalidade com que são tratados, como tarefas obrigatórias realizadas por atores definidos para cumpri-las.

De forma inversa, as práticas avaliativas desenvolvidas pelo Gestor-A1 e Gestor-B1, Gestor-B2 e Gestor-B3 não focam práticas avaliativas normativas. Esta realidade pode estar relacionada aos cargos e funções exercidos por estes profissionais na estrutura da gestão municipal, ou pode evidenciar a ausência de estímulo para produzir estratégias de atenção a partir de instrumentos normativos e que poderiam fortalecer as relações intergestoras do SUS, efetivando o trabalho em rede.

Essa evidência acentua a discussão sobre o papel das instâncias estadual e federal do SUS, como mediadoras de conhecimento e instigadoras de reflexões, para o desenvolvimento municipal e local. Por conseguinte, os desafios no uso dos RG, PMS e SIS disponíveis extra- 
polam a capacidade de se disponibilizar ferramentas de gestão para uso municipal, pensadas como incorporações de tecnologias duras e organizacionais normativas no cotidiano do trabalho das SMSs.

A importância do desenvolvimento destas ferramentas não é questionável, mas, por si só, não se mostram capazes de substituir o desenvolvimento gestor enquanto desenvolvimento humano para utilizá-las. Há, portanto, um distanciamento real das práticas avaliativas desenvolvidas localmente e das ferramentas de gestão disponíveis e estimuladas por atores externos ao contexto municipal.

Com o exposto, pensar em ferramentas de gestão no SUS significa pensar as tecnologias leves incorporadas nas relações entre os gestores, trabalhadores, usuários e outros atores na negociação diária de interesses na condução e uso dos recursos disponíveis no sistema. Assim, defende-se que, independentemente dos tipos de práticas avaliativas a utilizar, a gestão dos cuidados em saúde exige a inclusão de práticas qualitativas e participativas, produtoras de significados com os avaliados (Cohen e Franco, 2008; Pinheiro e Martins, 2009; Gerhardt et al., 2009c).

Dar visibilidade a essa dimensão da avaliação em saúde exige repensar a posição dos avaliadores - gestores, pesquisadores, população usuária etc. — como indutores não menos interessados, sempre capazes de enviesar o direcionamento da execução das políticas e planos de saúde. Desta forma, são incluídos como dimensões avaliativas as motivações e interesses, oficiais e oficiosos, que delineiam a execução da avaliação de programas e outras de pronunciamento estritamente técnico (Furtado, 2012) tendo em vista a dimensão das formas de reconhecimento (Honneth, 2003) na esfera social.

Longe de um posicionamento que prime por um afastamento destes atores nas práticas avaliativas em saúde, o reconhecimento dos seus posicionamentos - políticos e ideológicos - permite identificar a potencialidade na execução do SUS. Acredita-se que essa racionalidade, ao não eximir as contradições e limitações presentes na gestão do sistema, inclui elementos de análise importantes às regras do jogo em questão, que perpassam desde a elaboração de políticas de saúde e normatizações na esfera federal até a execução nas redes assistenciais e municipais do SUS.

\section{Considerações finais}

A escolha por essa discussão a partir de duas realidades distintas, utilizando-se de estudos de casos qualitativos, permitiu a problematização acerca das situações e condições das SMSs nas multiplicidades, incluídas suas atribuições e relações sociais. Desta forma, pode-se afirmar que o estudo conduziu ao reconhecimento da dimensão cotidiana, microssocial, das práticas avaliativas em saúde, mesmo com a existência de realidades distintas do SUS em cada um dos municípios.

Evidenciou que os acontecimentos no cotidiano dos espaços locais de gestão norteiam as práticas de cuidado na gestão. Apesar de normativas, as deliberações das demais esferas de gestão são indutoras, mas não definidoras. 
A hipótese é que as práticas avaliativas realizadas por agentes internos e por agentes externos, por serem motivadas por objetivos expressos por racionalidades diversas, também apresentam expressão executiva diversa, dificultando a integração entre os diferentes atores implicados no SUS. Essa hipótese resulta da conclusão de ausência de relação significativa estabelecida entre estas esferas, tendo em vista os relatos dos gestores entrevistados sobre a ausência de trocas, compartilhamento e construções afetivas de informações na gestão.

Com o exposto, afirma-se que reflexão sobre as dificuldades de efetivar e garantir a eficácia do sistema público de saúde ultrapassa a análise sobre sua eficiência técnica. Inclui a eficácia com vistas à satisfação dos usuários, que devem ser os destinatários principais das políticas de saúde, bem como os seus interesses e dos demais envolvidos com o setor — categorias profissionais, políticos locais e o mercado médico-hospitalar que age dentro do SUS.

Por sua dimensão, o presente estudo possibilitou a revisão das práticas avaliativas municipais em saúde no momento em que elas acontecem, considerando as perspectivas de seus atores envolvidos e a relação que têm com o espaço de atuação e os instrumentos disponíveis. A intenção de visibilizar essas práticas envolve a crença de que a gestão dos sistemas municipais de saúde, em municípios de pequeno porte, não é ao acaso ou apenas conduzida a partir de deliberações de atores externos à realidade local específica.

Conclui-se que identificar e caracterizar quem são os atores implicados no SUS, quais interesses defendem, qual a missão das SMS na esfera pública e as práticas avaliativas utilizadas qualifica a discussão sobre indicadores, PMSs, RGs e todos os outros instrumentos de gestão do setor saúde. Sobretudo, esta afirmação reforça a ideia de que a atuação gestora municipal envolve a mediação sociopolítica como principal estratégia para considerar a diversidade de atores e suas avaliações sobre um sistema de saúde que pretende atuar em rede e que tem a participação como diretriz constitucional.

\section{Referências}

BECK, Fábio de L. et al. Desenvolvimento rural na 'Metade Sul' do Rio Grande do Sul: sistemas de ralações, mecanismos e dinâmicas sociais e naturais. Relatório de pesquisa. Faculdade de Economia. Programa de Pós-Graduação em Desenvolvimento Rural, Programa de Pesquisa Interdisciplinar, Universidade Federal do Rio Grande do Sul, Porto Alegre, 2008.

BRASIL. Conselho Nacional de Saúde. Resolução no 196, de 10 de outubro de 1996. Dispõe sobre as diretrizes e normas regulamentadoras de pesquisa envolvendo seres humanos. Brasília (DF): Conselho Nacional de Saúde, 1996.

BRASIL. Ministério da Saúde. Avaliação para Melhoria da Qualidade da Estratégia Saúde da Família. Documento técnico. Brasília: Ministério da Saúde, 2005. Disponível em:<http://dtr2002.saude. gov.br/proesf/autoavaliacaoesf/index.htm>. Acesso em: 19 nov. 2009.

CAMPOS, Gastão V. S. Considerações sobre o processo de administração e gerência de serviços de saúde. In: CAMPOS, Gastão V. S.; MERHY, Emerson E.; NUNES, Everardo D. N. (Ed.). Planejamento sem normas. São Paulo: Hucitec, 1994. p. 9-31. 
COHEN, Ernesto; FRANCO, Rolando. Avaliação de projetos sociais. 8. ed. Petrópolis: Vozes, 2008.

CONTANDRIOPOULOS, André-Pierre et al. A avaliação na área da saúde: conceitos e métodos. In: HARTZ, Zulmira Maria A. (Ed.). Avaliação em saúde: dos modelos conceituais à prática na análise da implantação de programas. Rio de Janeiro: Fiocruz, 1997. p. 29-47.

DUBOIS, Carl-Ardy A.; CHAMPAGNE, François; BILODEAU, Henriette. Histórico da Avaliação. In: BROUSSELLE, Astrid et al. (Org.). Avaliação: conceitos e métodos. Rio de Janeiro: Editora Fiocruz, 2011. p. 19-39.

FURTADO, Juarez P.; LAPERRIERE, Hélène. Parâmetros e paradigmas em meta-avaliação: uma revisão exploratória e reflexiva. Ciênc. Saúde Coletiva, v. 17, n. 3, p. 695-705, 2012.

GERHARDT, Tatiana E. et al. Determinantes sociais e práticas avaliativas de integralidade em saúde: pensando a situação de adoecimento crônico em um contexto rural. In: PINHEIRO, Roseni; MARTINS, Paulo H. (Ed.). Avaliação em saúde na perspectiva do usuário: abordagem multicêntrica. Rio de Janeiro: Cepesq/IMS-Uerj; Recife: Editora Universitária UFPE; São Paulo: Abrasco, 2009c. p. 287-298.

GERHARDT, Tatiana E. et al. Fluxos e utilização de serviços de saúde: mobilidade e necessidades em saúde de usuários e novos desafios para a integralidade em saúde pública. Relatório de pesquisa. Escola de Enfermagem, Universidade Federal do Rio Grande do Sul, Porto Alegre, 2009b.

GERHARDT, Tatiana E. et al. Reconhecimento e estigma em uma comunidade rural: discutindo acesso, participação e visibilidade de usuários em situação crônica de adoecimento crônico. In: PINHEIRO, Roseni; MARTINS, Paulo H. (Org.). Avaliação em saúde na perspectiva do usuário: abordagem multicêntrica. Rio de Janeiro: Cepesq/IMS-Uerj; Recife: Editora Universitária UFPE; São Paulo: Abrasco, 2009a. p. 287-298.

GIL, Antônio C. Estudo de caso. São Paulo: Atlas, 2009.

HARTZ, Zulmira M. A.; CONTANDRIOPOULOS, André-Pierre. Integralidade da atenção e integração de serviços de saúde: desafios para avaliar a implantação de um "sistema sem muros". Cad. Saúde Pública, v. 20, Sup. 2, p. S331-S336, 2004.

HARTZ, Zulmira M. A.; FELISBERTO, Eronildo; VIEIRA-DA-SILVA, Ligia Maria. Meta-avaliação da Atenção Básica à Saúde: teoria e prática. Rio de Janeiro: Fiocruz, 2008.

HONNETH, Axel. Luta por reconhecimento: a gramática moral dos conflitos sociais. São Paulo: Ed. 34, 2003.

INSTITUTO BRASILEIRO DE GEOGRAFIA E ESTATÍSTICA. Diretoria de Pesquisas. Coordenação de População e Indicadores Sociais. Indicadores sociais municipais: uma análise dos resultados do universo do Censo Demográfico 2010. Rio de Janeiro: IBGE, 2011. (Série Estudos e Pesquisas: Informação Demográfica e Socioeconômica. Número 28).

MARTINS, Paulo Henrique. MARES (Metodologia de Análise de Redes do Cotidiano): aspectos conceituais e operacionais. In: PINHEIRO, Roseni; MARTINS, Paulo Henrique (Org.). Avaliação em saúde na perspectiva do usuário: abordagem multicêntrica. Rio de Janeiro: Cepesq/IMS-Uerj; Recife: Editora Universitária UFPE; São Paulo: Abrasco, 2009. p. 61-89. 
MINAYO, Maria Cecília S. O desafio do conhecimento. São Paulo: Hucitec, 2008.

PAIM, Jairnilson S. Avaliação em saúde: uma prática em construção no Brasil. In: HARTZ, Zulmira Maria A.; SILVA, Ligia Maria V. da (Ed.). Avaliação em saúde: dos modelos teóricos à prática na avaliação de programas e sistemas de saúde. Salvador: Edufba; Rio de Janeiro: Fiocruz, 2005. p. 9-13.

PINHEIRO, Roseni; MARTINS, Paulo Henrique. Construindo caminhos analíticos e integralizando a solidariedade de conhecimentos: operacionalização da pesquisa. In: PINHEIRO, Roseni; MARTINS, Paulo Henrique (Ed.). Avaliação em saúde na perspectiva do usuário: abordagem multicêntrica. Rio de Janeiro: Cepesq/IMS-Uerj; Recife: Editora Universitária UFPE; São Paulo: Abrasco, 2009. p. 27-36.

PINHEIRO, Roseni; SILVA JUNIOR, Aluisio G. Práticas avaliativas e as mediações com a integralidade em saúde: uma proposta para estudos de processos avaliativos na Atenção Básica. In: PINHEIRO, Roseni; SILVA JUNIOR, Aluisio G.; MATTOS, Rubem A. (Ed.). Atenção Básica e integralidade: contribuições para estudos de práticas avaliativas em saúde. Rio de Janeiro: Cepesc: IMS/Uerj; Recife: Editora Universitária UFPE; São Paulo: Abrasco, 2008. p. 17-41.

PINTO, Juliana Maciel. O uso da informação na gestão da Atenção Básica à Saúde: "informação para quê mesmo?” Trabalho de conclusão de curso (graduação) — Escola de Enfermagem, Universidade Federal do Rio Grande do Sul, Porto Alegre, 2008.

RIQUINHO, Deise Lisboa. A outra face dos determinantes sociais de saúde: subjetividades na construção do cotidiano individual e coletivo em uma comunidade rural. Porto Alegre, RS. Dissertação (mestrado) - Escola de Enfermagem, Universidade Federal do Rio Grande do Sul, Porto Alegre, 2009.

RIVERA, Francisco J. U. (Ed.); TESTA, Mario; MATUS, Carlos. Planejamento e programação em saúde: um enfoque estratégico. São Paulo: Cortez, 1989.

ROESE, Adriana. Fluxos e acesso de usuários a serviços de saúde de média complexidade no município de Camaquã, RS. Dissertação (mestrado) - Escola de Enfermagem, Universidade Federal do Rio Grande do Sul, Porto Alegre, 2005.

SILVA, Ligia Maria V. da. Conceitos, abordagens e estratégias para a avaliação em saúde. In: HARTZ, Zulmira Maria A.; SILVA, Ligia Maria V. da (Org.). Avaliação em saúde: dos modelos teóricos à prática na avaliação de programas e sistemas de saúde. Salvador: Edufba; Rio de Janeiro: Fiocruz, 2005, p. 15-39.

SILVA, Ligia Maria V. da; FORMIGLI, Vera Lúcia A. Avaliação em saúde: limites e perspectivas. Cad. Saúde Pública, v. 10, n. 1, p. 80-91, 1994.

TESTA, Mario. Pensar em saúde. Porto Alegre: Artes Médicas, 1992.

UCHIMURA, Kátia Y.; BOSI, Maria Lúcia M. A polissemia da qualidade na avaliação de programas e serviços de saúde: resgatando a subjetividade. In: BOSI, Maria Lúcia M.; MERCADO-MARTÍNEZ, Francisco J. (Ed.). Pesquisa qualitativa de serviços de saúde. 2. ed. Petrópolis (RJ): Vozes, 2007. p. 75-98. 
Juliana Maciel Pinto é mestre em enfermagem pela Universidade Federal do Rio Grande do Sul (UFRGS) e assistente de planejamento na Secretaria Municipal de Saúde de Porto Alegre (RS).E-mail: ju_pinto1@ yahoo.com.br.

Tatiana Engel Gerhardt é doutora em antropologia social pela Université de Bourdeux2 (França) e professora associada do curso de Saúde Coletiva da UFRGS. E-mail: tatiana.gerhardt@ufrgs.br. 